\title{
Influence of porosity characteristics on the variability in mechanical properties of high pressure die casting (HPDC) AlSi7MgMn alloys
}

\author{
Yijie Zhang*, Ewan Lordan, Kun Dou, Shihao Wang, Zhongyun Fan
}

Brunel Centre for Advanced Solidification Technology (BCAST), Brunel University London, Kingston Lane, Uxbridge UB8 3PH, United Kingdom

*Corresponding author. Tel.: +441895268538; Fax: +441895269758; E-mail address: yijie.zhang@brunel.ac.uk.

\begin{abstract}
To reveal the influence of porosity on the variability in mechanical properties of HPDC Al alloys, micro computed tomography was employed to investigate the morphology and 3D distribution of porosity in the tensile samples. Experimental results show that the variability in mechanical properties of HPDC AlSi7MgMn alloy is related to the pore size and total volume of the porosity. The maximum pore size is inversely proportional to the elongation of the alloy with T6 heat treatment, while the total volume porosity was found to decline with increasing elongation. A maximum pore size of approx. $1.3 \mathrm{~mm}$ in diameter was found to correspond to an elongation of $6.4 \%$. Once its maximum size reduced to less than $0.3 \mathrm{~mm}$, the elongation was found to improve to $9 \%-13.5 \%$ for the alloy. Compared to the average value of $8.8 \%, 236.6 \mathrm{MPa}, 296.0 \mathrm{MPa}$ for elongation, yield strength and ultimate tensile strength respectively for the porosity-free AlSi7MgMn samples produced by gravity casting, the HPDC AlSi7MgMn alloy has the similar strength level and improved elongation to an average level of $11.5 \%$. This indicates that the porosity level is a determined factor to the mechanical property variability and its size less than $0.3 \mathrm{~mm}$ has no significant adverse effect on the mechanical properties of the alloy. The elongation improvement in HPDC AlSi7MgMn alloy is attributed to the finer grain size with an average value of $10 \mu \mathrm{m}$ compared to the average value of $500 \mu \mathrm{m}$ for the gravity casting AlSi7MgMn alloy, and to the reduced size and uniform distribution of porosity resulting from the subsequent refinement in grain size.
\end{abstract}

Keywords: Variability; Mechanical property; Porosity; HPDC; Al alloys

\section{Introduction}

Cold chamber high pressure die casting (HPDC) has been widely used in automotive industry to produce Al alloy components with thin wall and complicated shapes due to its high productivity, relatively low cost [1-4], excellent mechanical properties and castability supported by the development of HPDC Al alloys [5-8]. In terms of the filling and solidification characteristics in HPDC, there are three types of metallic melt movement once the melt is transferred into the shot sleeve. The first movement occurs in the shot sleeve where the melt is forced to move forward by the plunger at a slow speed of approx. $0.2-0.3 \mathrm{~m} \cdot \mathrm{s}^{-1}$ until it approaches the inner gate of the mould. In the second movement, the melt is transported at a very high speed of approx. $2-4 \mathrm{~m} \cdot \mathrm{s}^{-1}$ to complete the filling of the die cavity. The third movement occurs during the intensification stage, which aims to feed solidification shrinkage by the movement of the last solidifying melt under a high intensification pressure typically between $20-100 \mathrm{MPa}$ [9-11]. Additionally, during intensification the majority of air entrapment resulting from fluid flow in the shot sleeve is compressed to a considerable small size under the applied pressure. The contribution of air 
entrapment to the final porosity content is a key factor in assessing the suitability of a cast component for heat treatment, in the presence of gas porosity blistering will occur during solution treatment and the component will be scrapped [11-13].Shrinkage porosity forms in the final stage solidification and its content depends on the design of the gating system and the filling parameters [14-16]. Whilst porosity can be reduced to an acceptable level using high integrity processing techniques, it is impossible to eliminate it completely due to the limited feeding capacity of the melt resulting from high cooling rates and the compromise between productivity and product quality.

Regarding the solidification characteristics during HPDC, the porosity defect resulting from air entrapment and solidification shrinkage is inevitable and affects the mechanical property variability [17-19]. Therefore, the control and reduction of porosity is the priority to improve the quality of the HPDC castings. With regards to air entrapment in the shot sleeve, numerous studies have aimed to optimise the plunger motion to avoid air entrapment caused by the formation of breaking waves due to non-optimal movement of the melt [16,20-25]. Another contribution to the total gas content is the formation of $\mathrm{H}_{2}$ by the reaction between the melt and lubricant, which typically consists of polymer wax, mineral oil and some form of surfactant [26]. For shrinkage porosity, there is an optimised melt speed at the inner gate depending on the dimensions of the component in order to deliver a relatively flow of melt into the die cavity. This ensures the die is completely filled before intensification and improves the efficiency of the feeding channels; whilst also serving to reduce the opportunity for secondary oxides and air entrapment [27].

Besides the optimisation of process parameters, the vacuum assisted HPDC process has been developed to minimise air entrapment and enhance the filling ability of the melt [2831]. With the addition of a vacuum station, this technology aims to reduce the air content in the entire cavity whilst also reducing the back pressures experienced during die filling by ensuring that the melt movement in both shot sleeve and die cavity occurs under a given vacuum [32]. Some reports suggest that the elongation (El) is improved with a proper vacuum process and the total volume of the porosity in final component is reduced to less than $2 \%$ compared to the value of $1-5 \%$ for the castings without vacuum [33-36]. The porosity size for traditional HPDC of ADC12 alloy $(10.77 \% \mathrm{Si}, 1.87 \% \mathrm{Cu}, 0.78 \% \mathrm{Fe}$, $0.78 \% \mathrm{Zn}, 0.2 \% \mathrm{Mn}, 0.17 \% \mathrm{Mg}$ ) can up to $2 \mathrm{~mm}$ [37] and is less than $0.15 \mathrm{~mm}$ for A390 alloy $(17.1 \% \mathrm{Si}, 4.5 \% \mathrm{Cu}, 0.56 \% \mathrm{Mg}, 0.32 \% \mathrm{Fe})$ under vacuum HPDC [38]. Vacuum assisted HPDC can benefit the reduction of the total volume of the porosity, but cannot eliminate the porosity and change the size distribution significantly [26]. In other words, the mechanical properties are not stable nor repeatable for each of the components produced. In the automotive industry, large safety factors are typically applied to account for the unpredictable nature of HPDC components. By developing a better understanding between the processing parameters, casting defects and mechanical properties, automobile manufacturers will be able to produce more informed safety factors resulting in significant reductions in vehicle weight.

The mechanical properties are more related to the maximum size of the defects and their location with respect to the specimen free surface $[4,26,39,40]$. Currently, the majority of researches focussed on the improvement of mechanical properties, and the influence of the porosity on the mechanical properties are still unclear.

In the present study, micro computed tomography (Micro-CT) was employed to reconstruct the 3D morphology and size distribution of porosity for the HPDC tensile 
samples. Combined with the tensile results, the influences of the porosity characteristics on the mechanical property behaviour are then discussed.
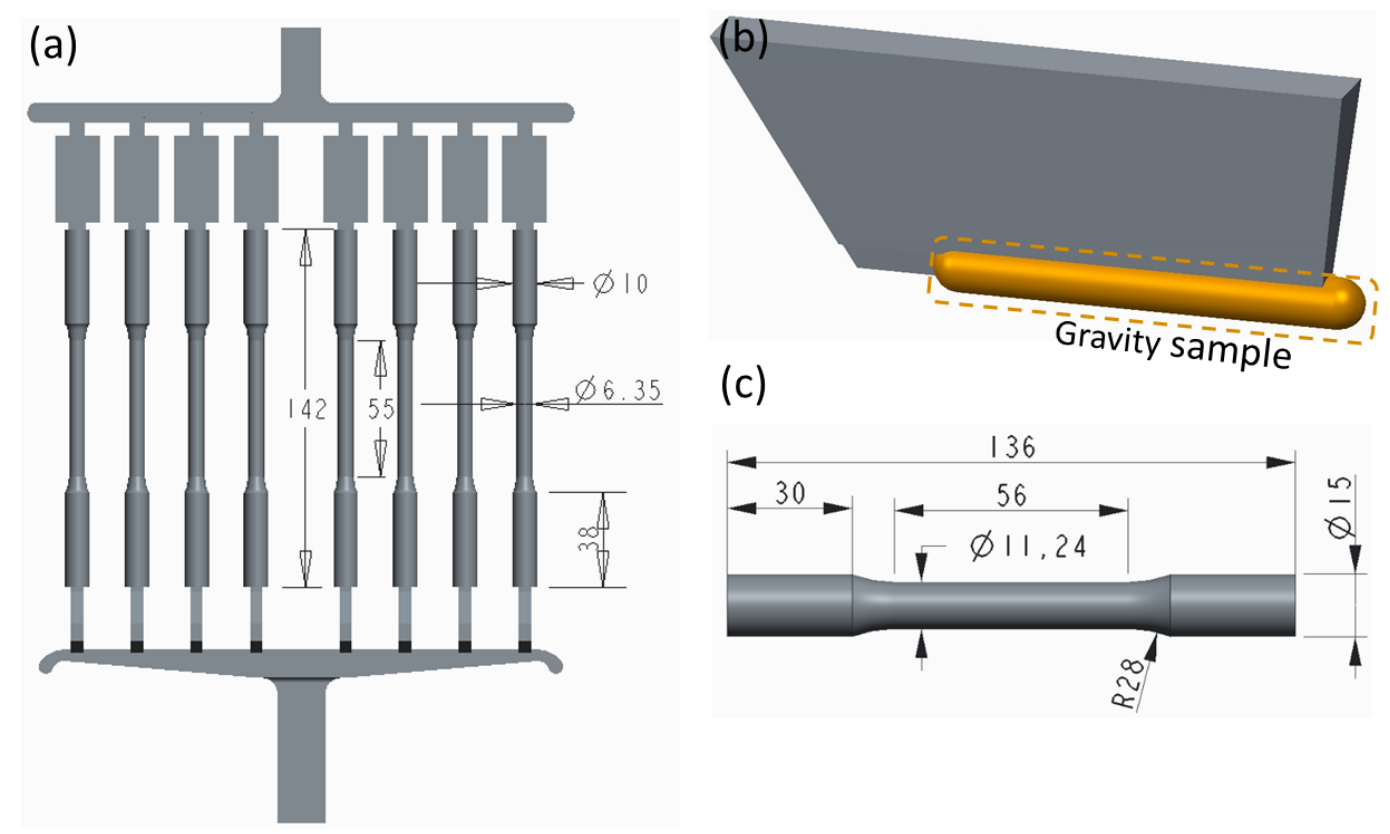

Figure 1 Geometry of the tensile samples (dimensions in $\mathrm{mm}$ ) prepared by HPDC (a), with eight samples produced in a single shot. The sample is obtained from the location of the gravity casting highlighted in (b), and subsequently machined to obtain the final dimension of the tensile sample (c).

\section{Experimental}

A356 alloy ingots supplied by Norton UK, was employed as the raw material in this study. To avoid soldering of the melt onto the die surface, $0.5 \% \mathrm{Mn}$ was added into A356 melt for carrying on HPDC experiments. The alloy compositions tested by foundry-master spectrometer mainly consist $7.5 \% \mathrm{Si}, 0.3 \% \mathrm{Mg}, 0.15 \% \mathrm{Fe}, 0.6 \% \mathrm{Mn}, 0.1 \% \mathrm{Ti}, 0.018 \% \mathrm{Sr}$, and $0.002 \% \mathrm{~B}$ (all in wt.\%). Clay-graphite crucible was then used with $35 \mathrm{Kg}$ of alloy per batch. When the melt temperature reached $725 \pm 5^{\circ} \mathrm{C}$, a half hour holding time was adopted to obtain the composition homogenization. The melt was then heated up further to $750^{\circ} \mathrm{C}$ for melt purification by rotary degassing technology for $12 \mathrm{~min}$ at $350 \mathrm{rpm}$ rotation speed, in which Ar was introduced to the bottom of the rotor with a flow rate of $41 / \mathrm{min}$. During rotary degassing, $0.2 \%$ of $\mathrm{Al}-10 \% \mathrm{Sr}$ and $0.2 \%$ of $\mathrm{Al}-5 \mathrm{Ti}-1 \mathrm{~B}$ master alloys were added into melt to achieve the modification of the eutectic Si and the grain refinement. The cleaned melt was then manually poured into the shot sleeve to produce tensile samples of $6.35 \mathrm{~mm}$ in diameter by a Frech $4500 \mathrm{kN}$ locking force cold chamber HPDC machine. The pouring temperature of the melt, die temperature and shot sleeve temperature were $680 \pm 5^{\circ} \mathrm{C}, 200 \pm 5^{\circ} \mathrm{C}$ and $180 \pm 5^{\circ} \mathrm{C}$ respectively. The geometry of the tensile samples (dimensions in $\mathrm{mm}$ ) prepared by HPDC processing is shown in Figure 1a. To obtain the porosity-free tensile sample as a baseline to show what kind of the porosity level is reasonable and acceptable for this alloy produced by HPDC, the permanent casting was used to obtain the gravity tensile samples, in which the pouring temperature and mould temperature were $700 \pm 5^{\circ} \mathrm{C}$ and $200 \pm 5^{\circ} \mathrm{C}$ respectively. The gravity sample was taken from the bottom of the casting as shown in figure $1 \mathrm{~b}$ with brown color and the dimension of the machined tensile sample is shown in figure 1c. 
After stabilization at room temperature for 24 hours, all the tensile samples underwent T6 heat treatment where solution occurred at $540 \pm 5^{\circ} \mathrm{C}$ for 30 minutes followed by water quenching and then ageing at $170 \pm 5^{\circ} \mathrm{C}$ for 2.5 hours. Tensile testing was carried out on an Instron 5500 Universal electromechanical testing system at ambient temperature. Ramping rate was $1 \mathrm{~mm} / \mathrm{min}$ and a $50 \mathrm{~mm}$ extensometer was used to record tensile data.

Samples for microstructural observation were prepared using standard metallurgical procedures, and microstructural analyses were carried out using a Zeiss optical microscope, Zeiss Supra 35VP field-emission scanning electron microscopy (FE-SEM) equipped with an energy dispersive X-ray spectroscopy (EDS) detector and electron backscatter diffraction (EBSD), and JEOL-2100 transmission electron microscopy (TEM), respectively. To reveal the 3D morphology in the HPDC samples, Micro-CT (Zeiss Xradia 410 Versa X-ray) was employed to identify the 3D characteristic of the porosities. To prepare samples for grain size analysis by EBSD technique, electrolytically polishing in a solution of nitric acid and methyl alcohol (1:4) under a temperature of $-30{ }^{\circ} \mathrm{C}$ was employed. OIM TSL software was used for the grain size statistical analysis.

\section{Results}

To assess the porosity level in tensile samples, ProCAST was employed to simulate the filling and solidification process for both gravity casting and HPDC process in present study [41]. Initial/boundary conditions of the casting process are set according to actual casting practice. In HPDC casting, the material of die and shot sleeve is $\mathrm{H} 13$ steel, and the initial temperature is $680^{\circ} \mathrm{C}, 200^{\circ} \mathrm{C}$ and $180^{\circ} \mathrm{C}$ for pouring temperature of the melt, die temperature and shot sleeve temperature respectively. While the pouring temperature and mould temperature is $700^{\circ} \mathrm{C}$ and $200^{\circ} \mathrm{C}$ for gravity casting. The interfacial heat transfer coefficient employed in simulation is $2000 \mathrm{~W} \cdot \mathrm{m}^{-2} \cdot \mathrm{K}^{-1}$ between melt and mould in gravity casting, $2000 \mathrm{~W} \cdot \mathrm{m}^{-2} \cdot \mathrm{K}^{-1}$ between melt and shot sleeve wall and $8000 \mathrm{~W} \cdot \mathrm{m}^{-2} \cdot \mathrm{K}^{-1}$ between melt and die in HPDC processing. The formation of shrinkage porosity during solidification is calculated using a decent NAPM model build in ProCAST.

(a)

(b)

(c)

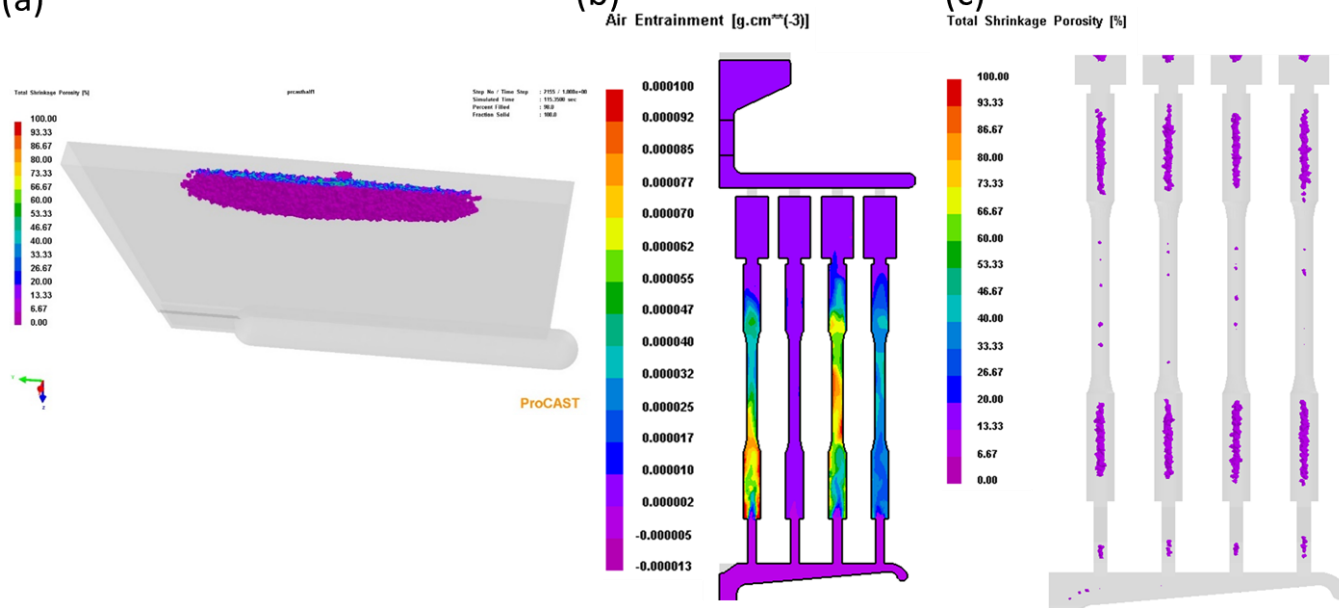

Figure 2 ProCAST simulations of total shrinkage porosity and air entrapment during solidification processing. In the gravity casting (a), shrinkage porosity was constrained to the riser section whilst no porosity was predicted within the sample itself. In the HPDC samples, the level of air entrapment (b) and shrinkage porosity (c) were found to vary with location in the casting. 


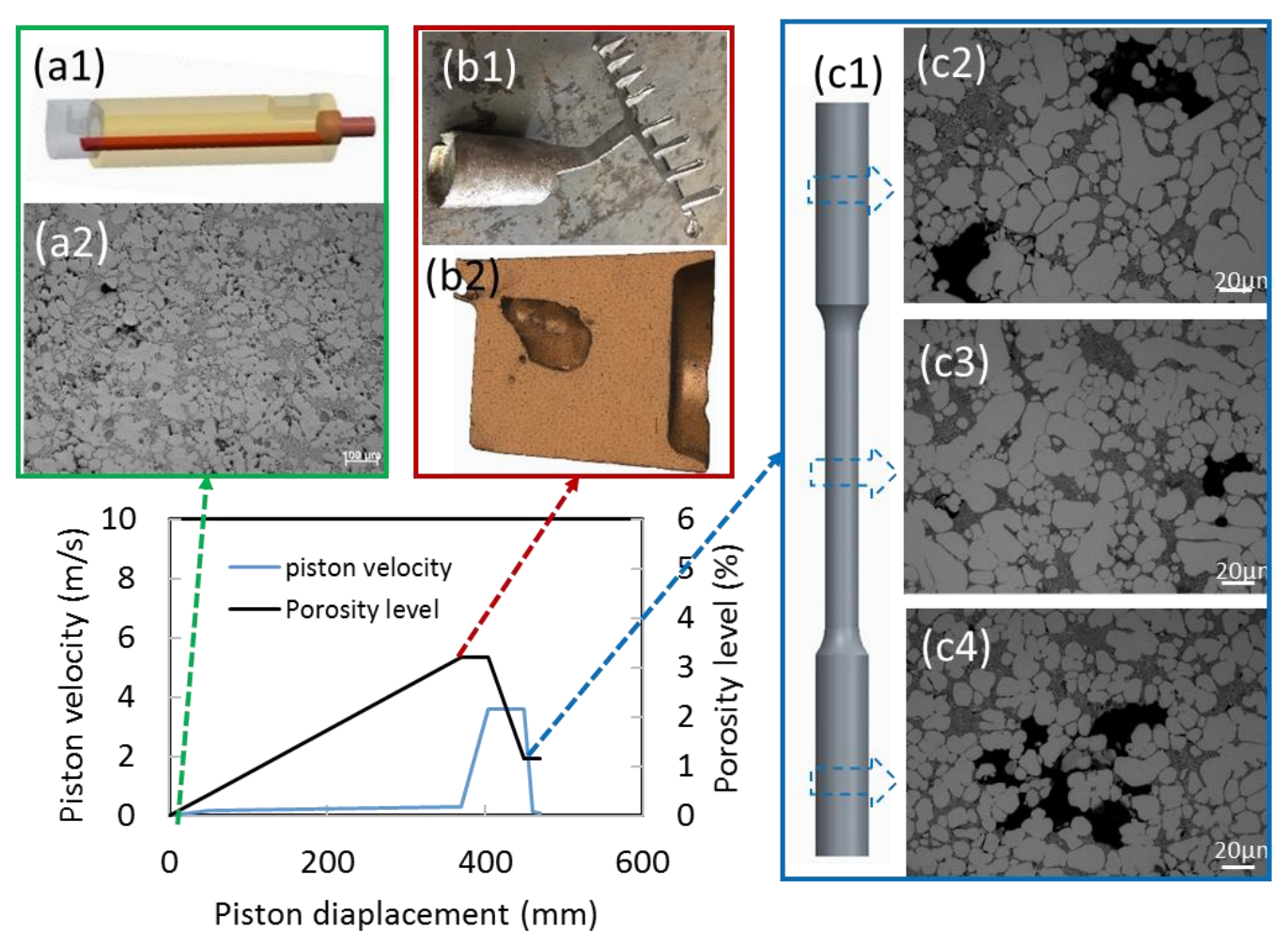

Figure 3 Evolution of porosity in the melt and final castings during the HPDC process. The melt at the beginning of piston motion was considering as a reference (a1). As indicated by the microstructure at this point (a2) there is no porosity in the ingot solidified in the shot sleeve. At the position of the melt reaching the inner gate showing in (b1), the content of the porosity increases up to about $3.5 \%$ and a large pore can be found in the biscuit (b2). At the final tensile samples (c1), the content of the porosity varies with position and its value is much higher at the grip section $(\mathrm{c} 2, \mathrm{c} 4)$ than at the gauge section (c3).

The shrinkage in gravity casting is shown in figure 2a. It indicates that the only possibility of shrinkage in gravity casting occurs in the top of the riser part other than in the tensile sample part. This means there is no obvious porosity for gravity tensile samples. Hence the gravity samples can be used as the porosity-free samples acting as the baseline properties.

In HPDC, the two major contributors to the total porosity content are air entrapment and solidification shrinkage, as shown in figure $2 \mathrm{~b}$ and $2 \mathrm{c}$ respectively. Obviously, a given level of the porosity exists inside the tensile sample varying with position. It is widely accepted that porosity adversely affects the El, tensile strength and fatigue life of cast components with factors such as defect size, morphology and spatial distribution having a significant impact on the mechanical properties [42-44]. In the HPDC filling process, air entrapment occurs during movement of the melt in the shot sleeve towards the inner gate, with an increase of approx.3.5\% (as shown in figure $3 \mathrm{~b}(1)$ and $3 \mathrm{~b}(2)$ ) porosity level reached compared to the initial melt condition after being poured into the shot sleeve (as shown in figure $3 \mathrm{a}(1)$ and $3 \mathrm{a}(2))$. At the final filling stage under high intensification pressure, such kind of air entrapment in the melt was forced into the die cavity and leading to porosity. Due to the high cooling rate in the HPDC process, the feeding capacity of the liquid melt into the component to fill the volumetric shrinkage caused by solidification is 
insufficient and results in shrinkage porosity. Therefore, the total porosity level varies with position in the final component. In the present study, the content of the porosity in the gauge section (figure $3 \mathrm{c}(3)$ ) of the tensile samples (figure $3 \mathrm{c}(1)$ ) is much less than that in the grip section (figure $3 \mathrm{c}(2)$ and $3 \mathrm{c}(4)$ ). These experimental results about the porosity distribution are in strong agreement with the simulation results (shown in figure $2 \mathrm{~b}$ and $2 \mathrm{c}$ ).
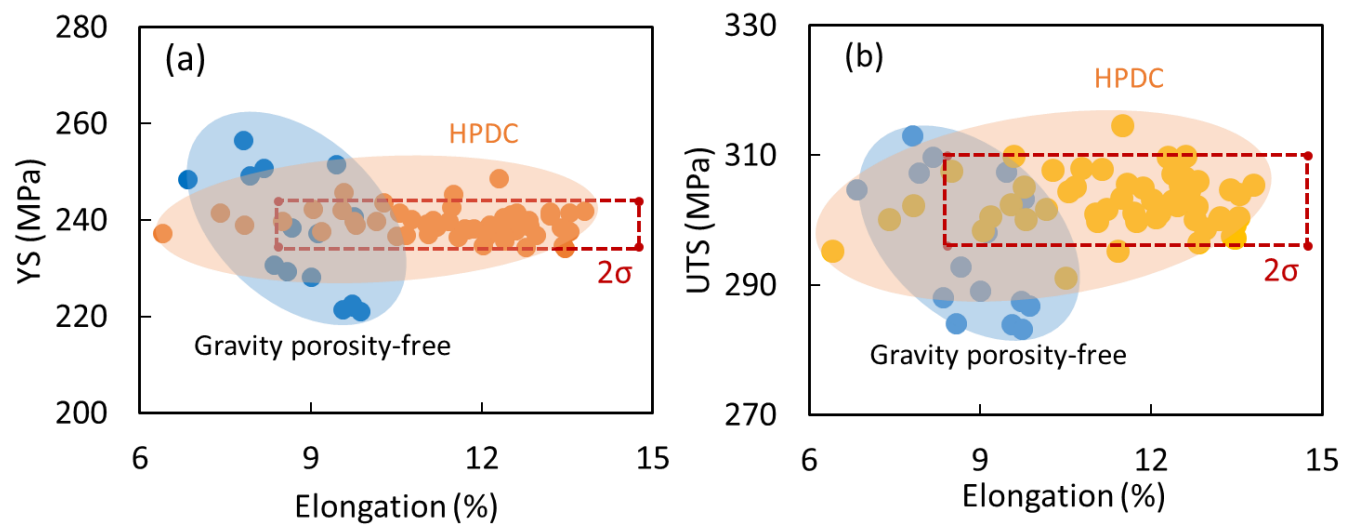

Figure 4 The YS and El of the samples at T6 heat treatment state for the alloy prepared by gravity casting and HPDC, and the $2 \sigma$ distribution of El and YS for the HPDC samples (a). The UTS and El of the samples at T6 heat treatment state for the alloy prepared by gravity casting and HPDC, and the $2 \sigma$ distribution of Eland UTS for the HPDC samples (b).

Table 1 The average and standard deviation $(\sigma)$ of the properties of the samples prepared by gravity casting and HPDC.

\begin{tabular}{cccccc}
\hline casting method & porosity status & & YS(MPa) & UTS(MPa) & El(\%) \\
\hline \multirow{2}{*}{ gravity } & \multirow{2}{*}{ porosity-free } & average & 236.6 & 296.0 & 8.8 \\
& & $\sigma$ & 12.1 & 10.3 & 0.9 \\
\multirow{2}{*}{ HPDC } & \multirow{2}{*}{ porosity } & average & 239.1 & 302.9 & 11.5 \\
& & $\sigma$ & 2.3 & 3.5 & 1.7 \\
\hline
\end{tabular}

Figure 4 shows the comparison between yield strength (YS), ultimate tensile streng th (UTS) and El for gravity casting and HPDC samples with T6 heat treatment. It can be seen that the distribution of YS and UTS for HPDC samples is narrower than that for gravity samples, while the El range of HPDC samples is wider than that of gravity porosity-free samples. For gravity samples, the average value of YS, UTS an El is $236.6 \mathrm{MPa}, 296.0 \mathrm{MPa}$ and $8.8 \%$ respectively, and is $239.1 \mathrm{MPa}, 302.9 \mathrm{MPa}$ and $11.5 \%$ for HPDC samples, as shown in table 1 . The comparison of the average value of the mechanical properties indicates that the YS and UTS for both gravity casting samples and HPDC samples are in the same level, whilst the El of the HPDC samples is much higher than that of the gravity samples. Regarding porosity as the main defect in the HPDC samples, a wider size distribution was accompanied by a higher El. This suggests that porosity indeed has a significant influence on the El, but more importantly the El depends on the size and morphology of the porosities and the uniform distribution of porosity will minimize its adverse effects on the El. The reduced standard deviation $(\sigma)$ in YS and UTS for HPDC 
samples, as shown in table 1, indicates that in addition to the defects, the microstructure such as grain size could also contribute to the observed property improvement.
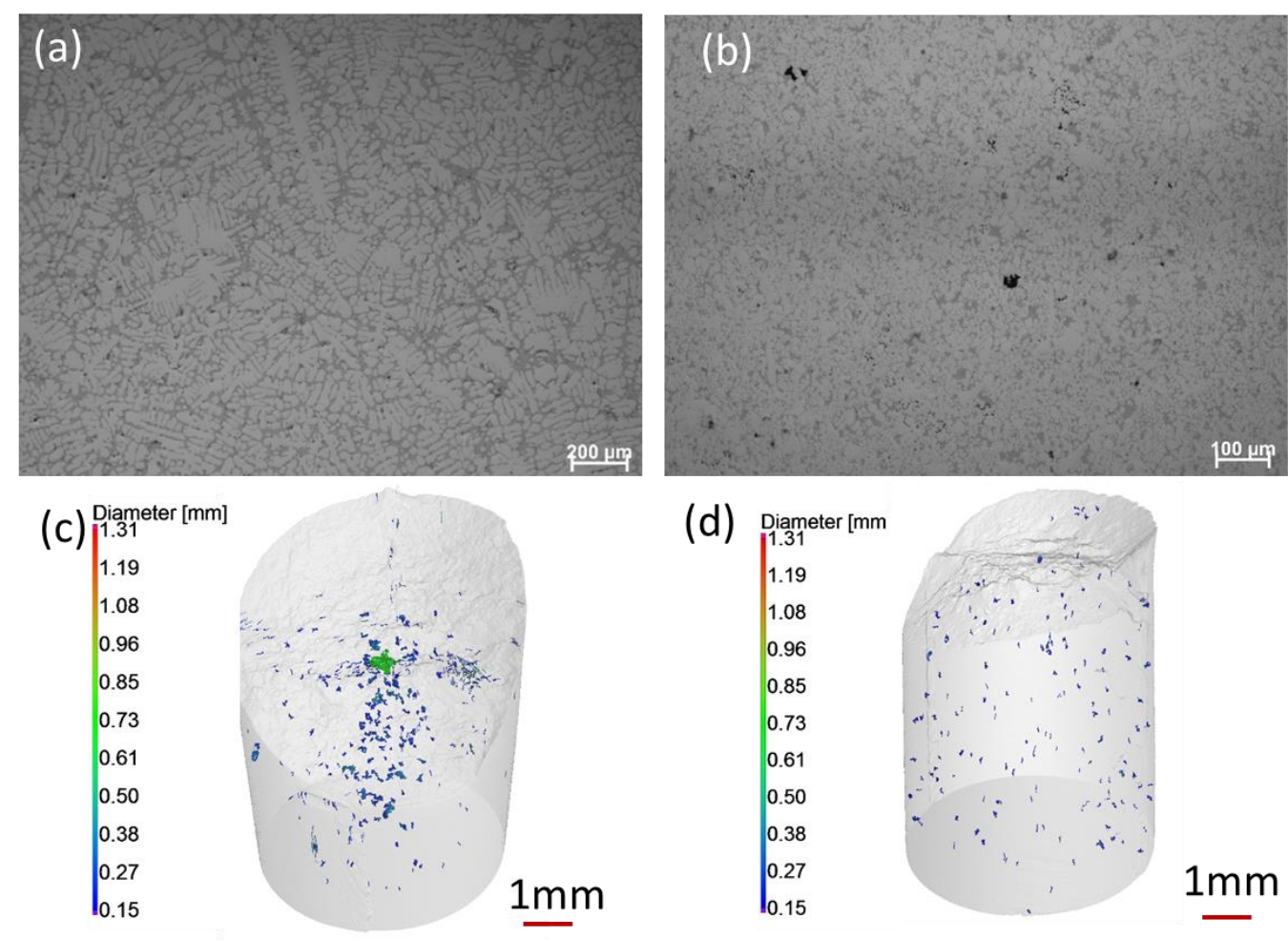

(d)

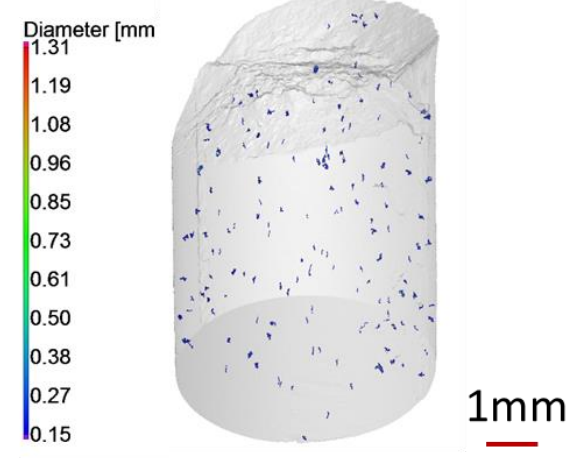

Figure 5 The microstructure indicates there is no porosity in gravity casting samples (a) and porosity in HPDC samples (b). The Micro-CT observation shows there are some huge porosities in HPDC samples with El about $6.4 \%$ having big size pores (c) and the porosity size is less than $100 \mu \mathrm{m}$ for the HPDC samples with El about $11.5 \%$ (d).

The microstructure in figure $5 \mathrm{a}$ and $5 \mathrm{~b}$ reveals that there is no porosity in gravity tensile samples and many pores exist in the HPDC tensile samples. This also demonstrates that the simulation results are in strong agreement with the experimental results. To analyse the effect of the porosities on the El of HPDC samples, the tested samples with El of $6.4 \%$ and $11.5 \%$ were selected for comparison purpose, in which the observation area is close to the fracture surface because of this location is more representative for the relationship between porosity and fracture than other areas. The Micro-CT results for the HPDC samples with the worst El of $6.4 \%$ and the average $\mathrm{El}$ of $11.5 \%$ are shown in figure $5 \mathrm{c}$ and $5 \mathrm{~d}$ respectively. For the sample with El of $6.4 \%$, there are some large pores locating in the central region of the tensile samples, while the pore size is quite small and uniformly distributed for the sample having El of $11.5 \%$. The size of the largest pore varies for the HPDC tensile samples and tends to decrease with El increasing and its value is about $1.3 \mathrm{~mm}, 0.5 \mathrm{~mm}, 0.3 \mathrm{~mm}, 0.24 \mathrm{~mm}$ and $0.2 \mathrm{~mm}$ for the samples with $\mathrm{El}$ of $6.4 \%, 7.4 \%, 9.0 \%$, $11.5 \%$ and $13.5 \%$ respectively, as shown in figure 6 . And the total volume of porosity declines with increasing El for the HPDC samples. The comparison in figure 6 shows the maximum pore size in the HPDC samples is less than $0.3 \mathrm{~mm}$ when the $\mathrm{El}$ is more than $9 \%$. For the sample with El of $6.4 \%$ and $7.4 \%$, the number fraction of pores larger than $0.3 \mathrm{~mm}$ in diameter is $9.8 \%$ and $3.1 \%$ and the volume fraction of pores larger than $0.3 \mathrm{~mm}$ in diameter is $63.9 \%$ and $20.4 \%$ respectively. Therefore, for HPDC component, pores larger 
than $0.3 \mathrm{~mm}$ in diameter are much more harmful to the tensile strength and El than the pores of smaller size.
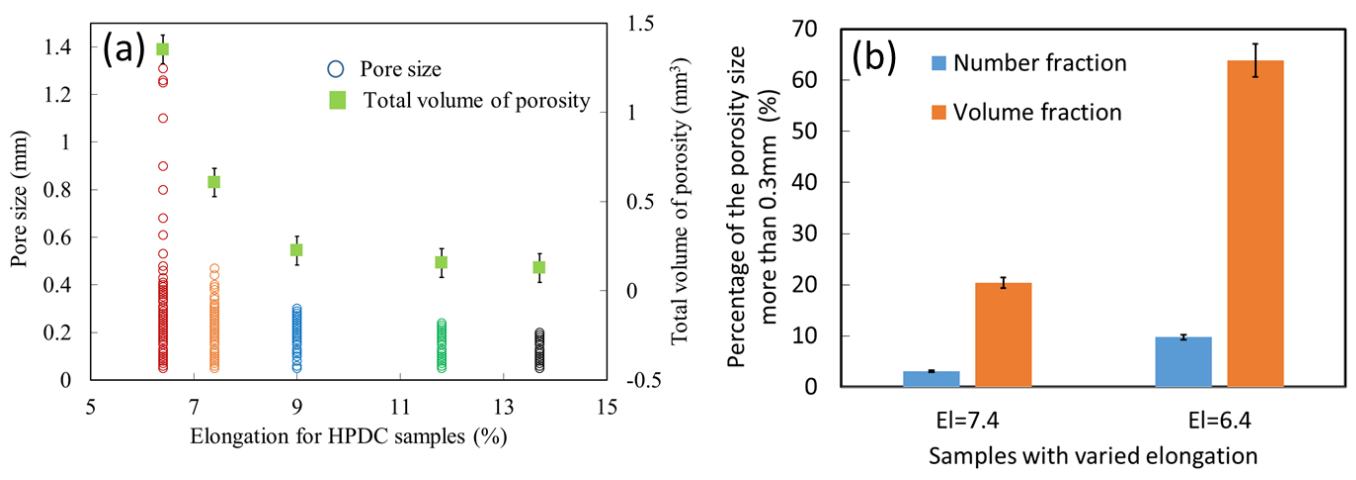

Figure 6 The porosity size distribution declines towards to less than $0.3 \mathrm{~mm}$ when the El more than $9 \%$, and the total volume of the porosities for the HPDC samples is decreased with the El increasing (a). The comparison of the number fraction and volume fraction of the porosity larger than $0.3 \mathrm{~mm}$ is revealed in (b).
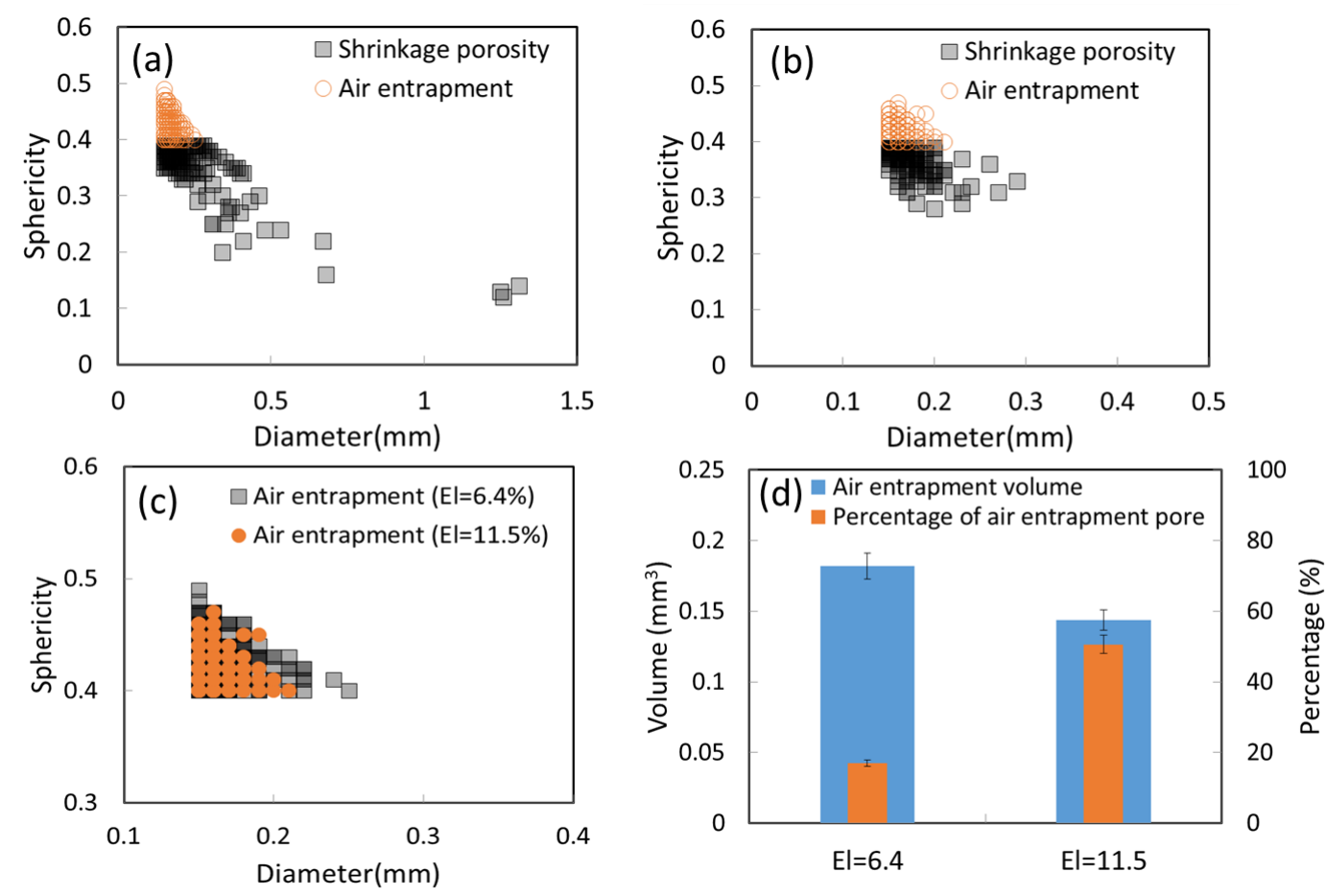

Figure 7 The sphericity of the porosity in the sample with elongation of $6.4 \%$ (a) and $11.5 \%$ (b), while a pore having sphericity value less than 0.4 means it is shrinkage porosity. (c) is a comparison of pores forming by air entrapment between samples having elongation of $6.4 \%$ and $11.5 \%$ respectively. (d) shows the volume and percentage of pore caused by air entrapment in samples having elongation of $6.4 \%$ and $11.5 \%$.

\section{Discussion}

For Al alloys produced by HPDC process, there are two types of porosity defects including air entrapment pore and shrinkage porosity due to the special filling characteristic. 
Regarding the micro-CT results, the sphericity is employed to distinguish the porosity type. Its value is between 0 and 1 where 1 means it is a perfect sphere. The criteria value of sphericity for the porosity type is 0.4 , while the value less than 0.4 indicates the porosity belongs to shrinkage porosity, and air entrapped pore has the sphericity more than 0.4 . The sphericity of porosity in HPDC samples having elongation of $6.4 \%$ and $11.5 \%$ is shown in figure $7 \mathrm{a}$ and $7 \mathrm{~b}$ respectively. There are similar trends in these two figures that the big porosities in diameter have relative lower sphericity. This reveals that the big pores in HPDC samples are contributed by shrinkage porosity. This kind of shrinkage porosity is much harmful than the pore having high sphericity to the mechanical properties of HPDC AlSi7MgMn alloy. The simulation result in figure $2 \mathrm{c}$ indicates that the shrinkage porosity varied with the sample location in the whole die cavity and also in the same sample as well. Both the experimental results and simulation results reveal that the shrinkage porosity is the main factor determining the variation in mechanical properties of HPDC A1Si7MgMn alloy. Comparison of the air entrapment in both HPDC samples having elongation of $6.4 \%$ and $11.5 \%$, as shown in figure $7 \mathrm{c}$, illustrates that the pores caused by air entrapment in high elongation samples are slightly smaller than that in low elongation samples.

Combination with the results in figure $7 \mathrm{c}$ and $7 \mathrm{~d}$ indicates that the air entrapment pores are towards to the small amount of total volume and the small size in diameter to the sample having a high elongation.

Figure 8 shows the fracture surface of HPDC AlSi7MgMn alloy having elongation of $6.4 \%$ and $11.5 \%$. It can be seen that there are some obvious pores on the fracture surface of both samples, and no other types of inclusions are found in these surface. This is well agreement with micro-CT results in figure 5 and indicates that the porosity is the main defect in HPDC A17SiMgMn alloys.
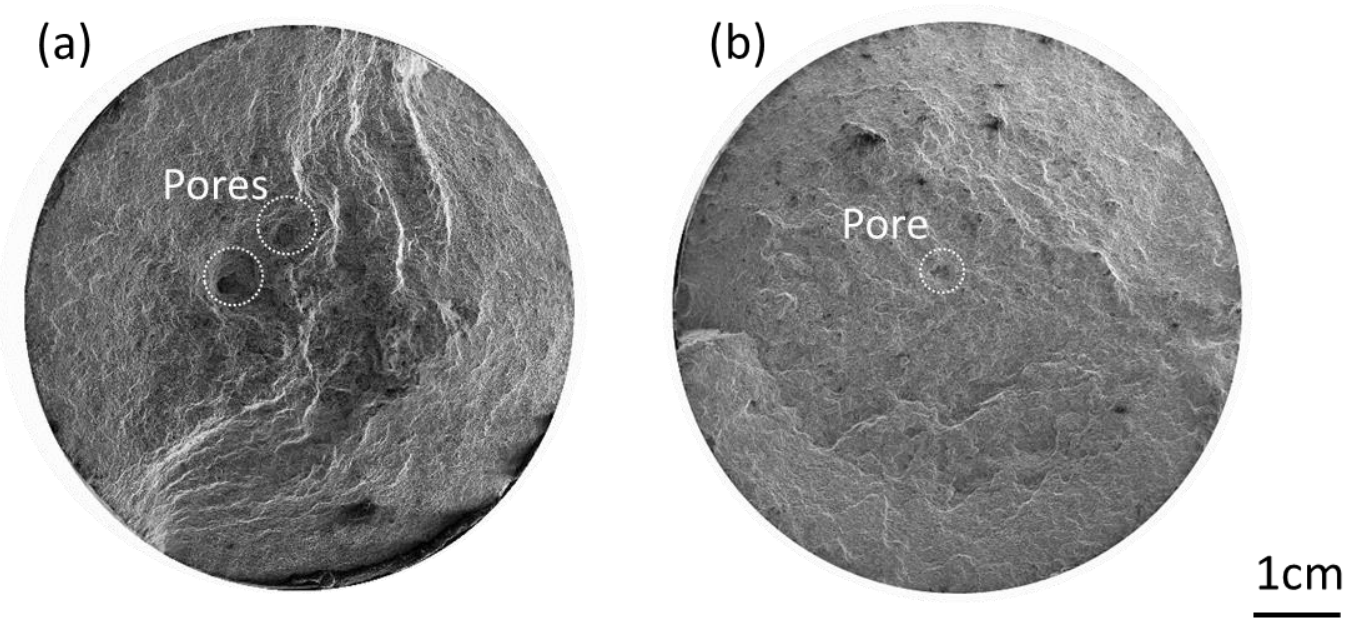

Figure 8 The fracture surface of HPDC A1Si7MgMn alloy having elongation of $6.4 \%$ (a) and $11.5 \%(b)$.

To disperse the porosity, grain refinement is an effective approach in Al alloys without introducing other adverse effects. In addition, it is an important strengthening mechanism to improve the YS strength of materials by reducing their grain size [45-47]. Hall-Petch is an effective model describing the relation between grain size and the increment in YS for the materials with grain size ranging from $1 \mathrm{~mm}$ to $1 \mu \mathrm{m}$ [48], the equation is as follows. 


$$
\Delta \sigma=K d^{-1 / 2}
$$

Where $d$ is average grain size in the unit of $\mu \mathrm{m}, k$ is a constant and typically equal to 40MPa for aluminium alloys.
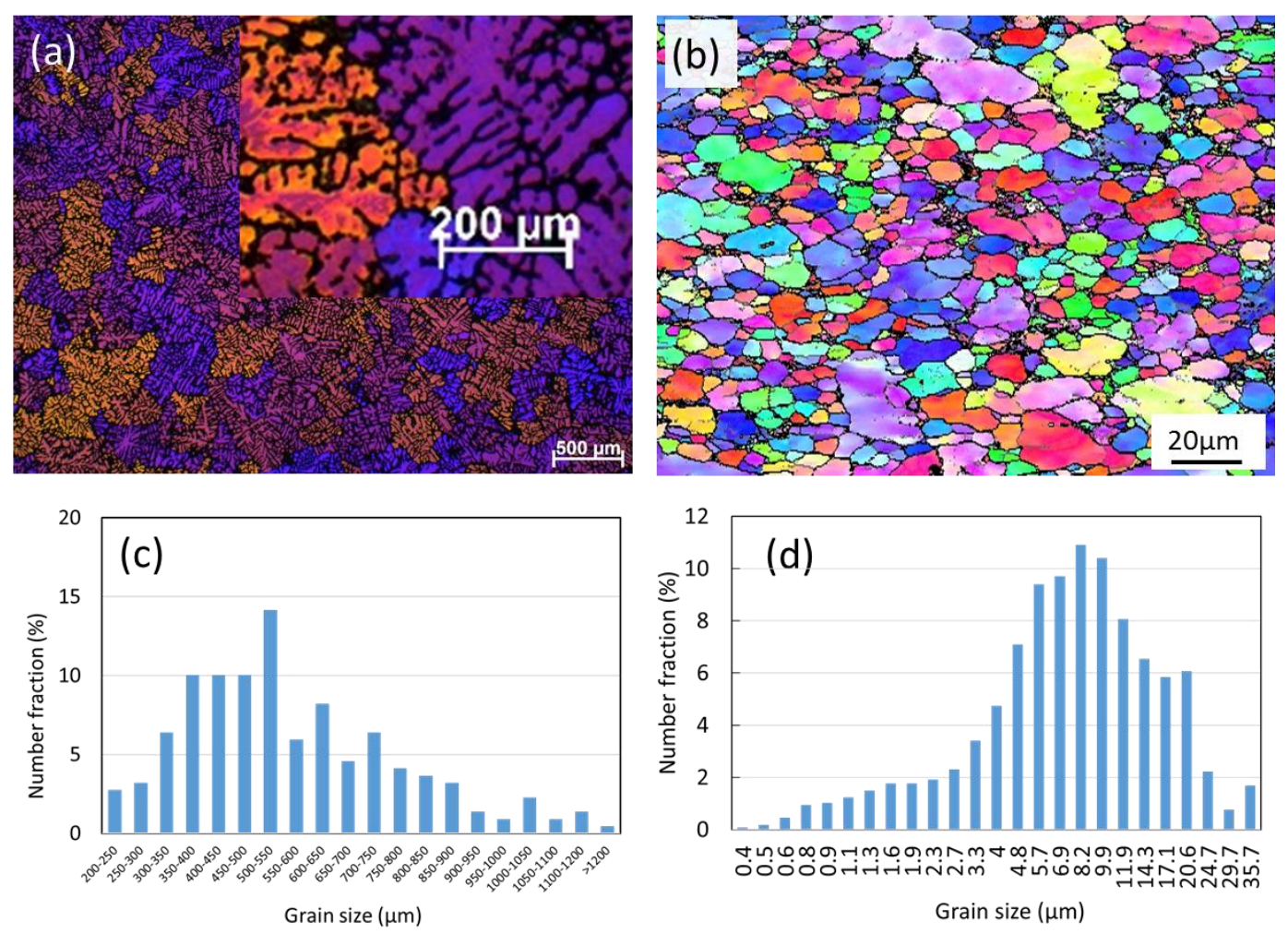

Figure 9 The microstructure shows the grain size of the alloy at as-cast state produced by gravity casting (a) and HPDC (b). The grain size distribution showing in (c) and (d) is for the alloy prepared by gravity casting and HPDC respectively.

The grain microstructure for gravity casting and HPDC tensile samples is shown in figure $9 \mathrm{a}$ and $9 \mathrm{~b}$ respectively. The microstructure comparison illustrates that the grain size of the HPDC sample is much smaller than that of the gravity sample. The average grain size of the gravity sample is about $500 \mu \mathrm{m}$ and about $10 \mu \mathrm{m}$ for HPDC sample, as shown in figure $9 \mathrm{c}$ and $9 \mathrm{~d}$. According to the Hall-Petch model, the contribution of the grain size of $500 \mu \mathrm{m}$ to the increment of the YS is about $1.8 \mathrm{MPa}$, while the increment is about $12.7 \mathrm{MPa}$ for the grain size of $10 \mu \mathrm{m}$. However, the average YS for gravity casting and HPDC samples is in the same level and its value is about $236.6 \mathrm{MPa}$ and $239.1 \mathrm{MPa}$ respectively, as seen in table 1. Further investigation in the grain microstructure reveals that the grain morphology for gravity casting samples is dendrite crystal and is globular for HPDC samples. Within the dendritic structure, there are many secondary dendrite arms with an average spacing of $20 \mu \mathrm{m}$, as shown in the insert image in figure $9 \mathrm{a}$. The fine secondary dendrite arm spacing (SDAS) has proved that it can cause a general increase in YS, UTS and El for materials [49-52]. If taking the SDAS into account when predicting the YS by Hall-Petch model, the increment is about $8.9 \mathrm{MPa}$ for the gravity casting samples. Basing on the prediction results of the increment of about $12.7 \mathrm{MPa}$ for the HPDC samples, there is a value of $3.7 \mathrm{MPa}$ higher than gravity samples. This is well agreed with experimental results that the average YS for HPDC samples is $2.5 \mathrm{MPa}$ higher than that for the gravity samples. In addition to 
the contribution of the fine grain size to the YS enhancement, grain refinement will result in a more uniform spatial distribution of porosity, minimizing their deteriorating effects on the tensile properties.

For A356 alloy, the modification of eutectic Si from coarse acicular flake shape to a fibrous rod like form [53-55] is necessary to reduce its adverse influence on the El. Sr was employed in the present study to achieve the modification of eutectic Si. It should be noted that the eutectic Si is very fine for both gravity and HPDC samples in the as-cast state, as shown in figure 10a and 10c respectively. This means that the modification is good enough to spheroidise eutectic Si via solution heat treatment at $540 \pm 5^{\circ} \mathrm{C}$. With the help of the solid diffusion at a relative high temperature, the eutectic Si can be tailored to a spheroid morphology and coarsened to some degree by prolonging the holding time. In the present study, the Si size ranging from 1 to $10 \mu \mathrm{m}$ in diameter is obtained for gravity and HPDC samples as shown in figure $10 \mathrm{~b}$ and $10 \mathrm{~d}$ respectively.
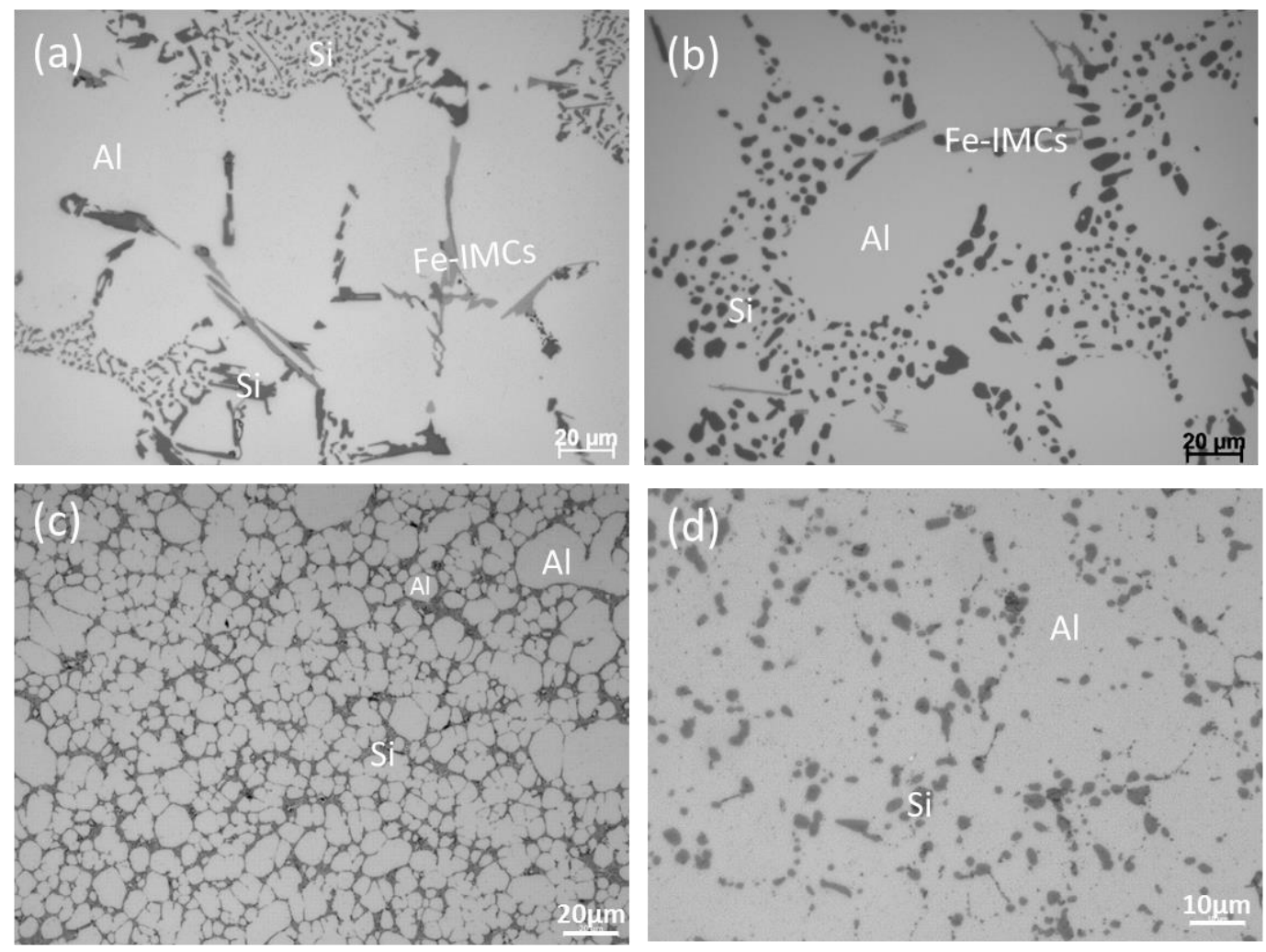

Figure 10 The morphology of eutectic Si in gravity casting AlSi7MgMn alloy at as-cast state (a) and T6 heat treatment state (b). The Si morphology in HPDC AlSi7MgMn alloy at as-cast state and T6 heat treatment state is shown in (c) and (d) respectively. 

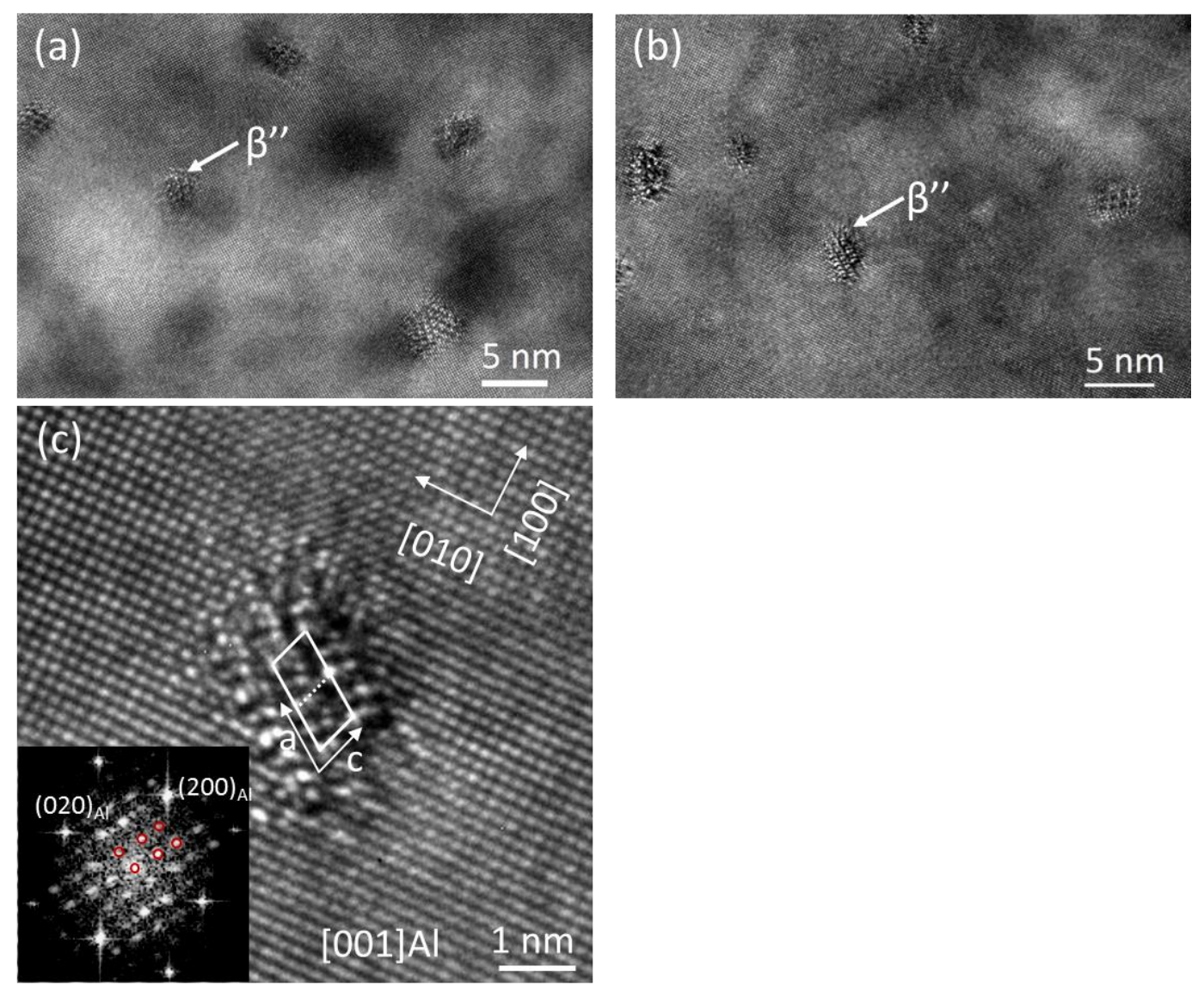

Figure 11 The precipitates in AlSi7MgMn alloys after T6 heat treatment with gravity casting (a) and HPDC (b), and (c) a typical high resolution TEM image of one precipitates in (b), the inset is FFT pattern. The precipitate was identified to be $\beta$ " with a monoclinic structure and the orientation relationship is $\langle 230\rangle_{\mathrm{Al}} / /\langle 100\rangle_{\beta}{ }^{\prime},\langle-310\rangle_{\mathrm{Al}} / /\langle 001\rangle_{\beta}$ ",

A proper ageing treatment after the solution process can promote the formation of the precipitates according to the chemical composition, resulting in the enhancement of strength. This is another important strengthening mechanism for Al alloys called precipitation strengthening [10,56,57]. For Al-Si-Mg based alloys, the possible precipitates are $\beta$ ' $\left(\mathrm{Mg}_{5} \mathrm{Si}_{6}\right), \beta$ ' $\left(\mathrm{Mg}_{9} \mathrm{Si}_{5}\right)$ and $\beta\left(\mathrm{Mg}_{2} \mathrm{Si}\right)$ phase [58-60]. The needle-like monoclinic $\beta$ "'-precipitate having a lattice constants of $a=1.53 \mathrm{~nm}, b=0.405 \mathrm{~nm}, c=0.67 \mathrm{~nm}$ and $\gamma=106^{\circ}$ is considered as the most effective hardening precipitates among all types of precipitates in $\mathrm{Al}-\mathrm{Mg}-\mathrm{Si}$ alloys $[61,62]$. In the present study, natural ageing prior to the artificial ageing is an important process to form the pre- $\beta$ " clusters containing $\mathrm{Si}$ and $\mathrm{Mg}$ atoms as a precursor for the following artificial ageing at $170 \pm 5^{\circ} \mathrm{C}$ for 2.5 hours to produce $\beta$ ''-precipitates. The precipitates for gravity samples and HPDC samples are shown in figure $11 \mathrm{a}$ and $11 \mathrm{~b}$ respectively. The size of about $5 \mathrm{~nm} \times 5 \mathrm{~nm}$ to the precipitates along a $\langle 001\rangle_{\mathrm{Al}}$ orientation is well agreed with other reports that the size of needle-like monoclinic $\beta$ "'-precipitate is about $4 \mathrm{~nm} \times 4 \mathrm{~nm} \times 50 \mathrm{~nm}$ [62]. The fast Fourier transformation (FFT) image pattern in figure 11c confirms that the precipitate presented in figure $11 \mathrm{a}$ and $11 \mathrm{~b}$ is $\beta$ " phase, and there is an orientation relation between $\mathrm{Al}$ and $\beta$ "' phase: $[230]_{\mathrm{Al}} / /[100]_{\beta}$, and $[-310]_{\mathrm{Al}} / /[001]_{\beta}$. In term of the size of $\beta$ ' phase and the content of Mg in both gravity samples and HPDC samples are exactly the same, the contribution of the precipitates to the strength should be at the same level. In addition, the improvement of strength contributed by precipitation strengthening will decrease the $\mathrm{El}$ of 
the alloy. In other words, the improvement in the El for HPDC samples is not attributed to precipitation strengthening.

In terms of the elongation of HPDC samples having the big porosities is lower than that of gravity casting samples, this means that the porosity is a key factor when its size beyond a critical size. Once the porosity level less than the critical value, its influence on the property still exists but it is acceptable because of the elongation is higher enough in meeting design criteria. Basing on the analysis mentioned above, the improvement of elongation for HPDC samples benefits from the uniform distributed smaller porosities and the small grain size.

\section{Conclusions}

Compared to the air entrapment pores, the shrinkage porosity is a dominant cause to the variation in mechanical properties of HPDC AlSi7MgMn alloys, in which the maximum pore size is sensitive to the elongation of the alloy. The elongation of the HPDC AlSi7MgMn alloy increases as the largest pore size decreases, with the total volume of the porosity found to be relatively low for high elongation samples. A pore size of $0.3 \mathrm{~mm}$ was critical to HPDC AlSi7MgMn alloy aiming having an elongation more than 9\%.

\section{Data availability statement}

The datasets generated and analysed during the current study are available from the corresponding authors on reasonable request.

\section{Acknowledgements}

This project is financially supported by EPSRC UK in the EPSRC Centre for Innovative Manufacturing in Liquid Metal Engineering (The EPSRC Centre-LiME).

\section{References}

[1] Jung JG, Ahn TY, Cho YH, Kim SH, Lee JM. Synergistic effect of ultrasonic melt treatment and fast cooling on the refinement of primary Si in a hypereutectic Al-Si alloy. Acta Mater 2018;144:31-40. https://doi.org/10.1016/j.actamat.2017.10.039.

[2] Cleary PW, Ha J, Prakash M, Nguyen T. 3D SPH flow predictions and validation for high pressure die casting of automotive components. Appl Math Model 2006;30:1406-27. https://doi.org/10.1016/j.apm.2006.03.012.

[3] Timelli G, Bonollo F. The influence of Cr content on the microstructure and mechanical properties of AlSi9Cu3(Fe) die-casting alloys. Mater Sci Eng A 2010;528:273-82. https://doi.org/10.1016/j.msea.2010.08.079.

[4] Hsu QC, Do AT. Minimum porosity formation in pressure die casting by taguchi method. Math Probl Eng 2013;2013:1-9. https://doi.org/10.1155/2013/920865.

[5] Zhu X, Blake P, Dou K, Ji S. Strengthening die-cast Al-Mg and Al-Mg-Mn alloys with Fe as a beneficial element. Mater Sci Eng A 2018;732:240-50.

https://doi.org/10.1016/j.msea.2018.07.005.

[6] Zhang P, Li Z, Liu B, Ding W. Tensile Properties and Deformation Behaviors of a New Aluminum Alloy for High Pressure Die Casting. J Mater Sci Technol 2017;33:367-78. https://doi.org/10.1016/j.jmst.2016.02.013. 
[7] Xu C, Zhao J, Guo A, Li H, Dai G, Zhang X. Effects of injection velocity on microstructure, porosity and mechanical properties of a rheo-diecast Al-Zn-Mg-Cu aluminum alloy. J Mater Process Technol 2017;249:167-71.

https://doi.org/10.1016/j.jmatprotec.2017.05.033.

[8] Ji S, Watson D, Fan Z, White M. Development of a super ductile diecast Al-Mg-Si alloy. Mater Sci Eng A 2012;556:824-33. https://doi.org/10.1016/j.msea.2012.07.074.

[9] Zhang Y, Patel JB, Lazaro-Nebreda J, Fan Z. Improved Defect Control and Mechanical Property Variation in High-Pressure Die Casting of A380 Alloy by High Shear Melt Conditioning. JOM 2018;70:2726-30. https://doi.org/10.1007/s11837-018-3005-y. [10] Zhang Y, Wang S, Lordan E, Wang Y, Fan Z. Improve mechanical properties of high pressure die cast A19Si3Cu alloy via dislocation enhanced precipitation. J Alloys Compd 2019;785:1015-22. https://doi.org/10.1016/j.jallcom.2019.01.278.

[11] Ozhoga-Maslovskaja O, Gariboldi E, Lemke JN. Conditions for blister formation during thermal cycles of Al-Si-Cu-Fe alloys for high pressure die-casting. Mater Des 2016;92:151-9. https://doi.org/10.1016/j.matdes.2015.12.003.

[12] Lumley RN, Odonnell RG, Gunasegaram DR, Givord M. Heat treatment of highpressure die castings. Metall Mater Trans A 2007;38:2564-74.

https://doi.org/10.1007/s11661-007-9285-4.

[13] Lumley RN, Polmear IJ, Groot H, Ferrier J. Thermal characteristics of heat-treated aluminum high-pressure die-castings. Scr Mater 2008;58:1006-9.

https://doi.org/10.1016/j.scriptamat.2008.01.031.

[14] Kwon HJ, Kwon HK. Computer aided engineering (CAE) simulation for the design optimization of gate system on high pressure die casting (HPDC) process. Robot Comput Integr Manuf 2019;55:147-53. https://doi.org/10.1016/j.rcim.2018.01.003.

[15] Hu BH, Tong KK, Niu XP, Pinwill I. Design and optimisation of runner and gating systems for the die casting of thin-walled magnesium telecommunication parts through numerical simulation. J Mater Process Technol 2000;105:128-33.

https://doi.org/10.1016/S0924-0136(00)00546-X.

[16] Gunasegaram DR, Givord M, O'Donnell RG, Finnin BR. Improvements engineered in UTS and elongation of aluminum alloy high pressure die castings through the alteration of runner geometry and plunger velocity. Mater Sci Eng A 2013;559:276-86.

https://doi.org/10.1016/j.msea.2012.08.098.

[17] Fu J. Uncertainty Quantification on industrial high pressure die casting process. Purdue University, 2016.

[18] Li X, Xiong SM, Guo Z. On the porosity induced by externally solidified crystals in high-pressure die-cast of AM60B alloy and its effect on crack initiation and propagation. Mater Sci Eng A 2015;633:35-41. https://doi.org/10.1016/j.msea.2015.02.078.

[19] Yang Q, Guan K, Bu F, Zhang Y, Qiu X, Zheng T, et al. Microstructures and tensile properties of a high-strength die-cast Mg-4Al-2RE-2Ca-0.3Mn alloy. Mater Charact 2016;113:180-8. https://doi.org/10.1016/j.matchar.2016.01.024.

[20] Bill Andresen. Die casting engineering: A hydraulic, thermal, and mechanical process. CRC Press; 2004.

[21] Otarawanna S, Laukli HI, Gourlay CM, Dahle AK. Feeding mechanisms in highpressure die castings. Metall Mater Trans A Phys Metall Mater Sci 2010;41:1836-46. https://doi.org/10.1007/s11661-010-0222-6.

[22] Adamane AR, Arnberg L, Fiorese E, Timelli G, Bonollo F. Influence of injection parameters on the porosity and tensile properties of high pressure die cast Al-Si alloys: A review. Int J Met 2015;9:43-54. https://doi.org/10.1007/BF03355601. 
[23] Yu W, Yuan Z, Guo Z, Xiong S. Characterization of A390 aluminum alloy produced at different slow shot speeds using vacuum assisted high pressure die casting. Trans Nonferrous Met Soc China 2017;27:2529-38. https://doi.org/10.1016/S1003-6326(17)60281-4.

[24] Muhammed KA, Waly M, El-Gayyar MS. The effect of high pressure die casting parameter on the porosity and mechanical properties of Aluminum Silicon ADC12 alloy. Curret Sci Int 2017;6:872-9. https://doi.org/10.1007/BF03355601.

[25] Outmani I, Fouilland-Paille L, Isselin J, El Mansori M. Effect of Si, Cu and processing parameters on Al-Si-Cu HPDC castings. J Mater Process Technol 2017;249:559-69. https://doi.org/10.1016/j.jmatprotec.2017.06.043.

[26] Wang L, Turnley P, Savage G. Gas content in high pressure die castings. J Mater Process Technol 2011;211:1510-5. https://doi.org/10.1016/j.jmatprotec.2011.03.024. [27] Gunasegaram DR, Finnin BR, Polivka FB. Melt flow velocity in high pressure die casting: its effect on microstructure and mechanical properties in an Al-Si alloy. Mater Sci Technol 2007;23:847-56. https://doi.org/10.1179/174328407X176992.

[28] Yu W, Cao Y, Li X, Guo Z, Xiong S. Determination of Interfacial Heat Transfer Behavior at the Metal / Shot Sleeve of High Pressure Die Casting Process of AZ91D Alloy. J Mater Sci Technol 2017;33:52-8. https://doi.org/10.1016/j.jmst.2016.02.003.

[29] Jorstad J, Apelian D. Pressure assisted processes for high integrity aluminum castings. Int J Met 2008;8:19-39. https://doi.org/10.1007/BF03355420.

[30] Nandakumar V. process and tool design for the high integrity die casting of aluminum and magnesium alloys. The Ohio state University, 2014.

[31] Dong X, Zhu X, Ji S. Effect of super vacuum assisted high pressure die casting on the repeatability of mechanical properties of Al-Si-Mg-Mn die-cast alloys. J Mater Process Technol 2019;266:105-13. https://doi.org/10.1016/j.jmatprotec.2018.10.030.

[32] Niu XP, Hu BH, Pinwill I, Li H. Vacuum assisted high pressure die casting of aluminium alloys. J Mater Process Tech 2000;105:119-27. https://doi.org/10.1016/S09240136(00)00545-8

[33] dos Santos SL, Antunes RA, Santos SF. Influence of injection temperature and pressure on the microstructure, mechanical and corrosion properties of a $\mathrm{AlSiCu}$ alloy processed by HPDC. Mater Des 2015;88:1071-81. https://doi.org/10.1016/j.matdes.2015.09.095.

[34] Xu C, Zhao J, Guo A, Li H, Dai G, Zhang X. Effects of injection velocity on microstructure, porosity and mechanical properties of a rheo-diecast Al-Zn-Mg-Cu aluminum alloy. J Mater Process Technol 2017;249:167-71.

https://doi.org/10.1016/j.jmatprotec.2017.05.033.

[35] Wang J, Guo Z, Jiao XY, Xiong SM. On the formation mechanism of the ring-like microstructure of high-pressure die-cast A390 alloy. Mater Charact 2018;140:179-88. https://doi.org/10.1016/j.matchar.2018.04.012.

[36] Dargusch MS, Dour G, Schauer N, Dinnis CM, Savage G. The influence of pressure during solidification of high pressure die cast aluminium telecommunications components. $\mathrm{J}$

Mater Process Technol 2006;180:37-43. https://doi.org/10.1016/j.jmatprotec.2006.05.001. [37] Wan Q, Zhao H, Zou C. Effect of Micro-porosities on Fatigue Behavior in Aluminum Die Castings by 3D X-ray Tomography Inspection. ISIJ Int 2014;54:511-5. https://doi.org/10.2355/isijinternational.54.511.

[38] Hu Q, Zhao H, Li F. Microstructures and properties of SiC particles reinforced aluminum-matrix composites fabricated by vacuum-assisted high pressure die casting. Mater Sci Eng A 2017;680:270-7. https://doi.org/10.1016/j.msea.2016.10.090.

[39] Li X, Xiong SM, Guo Z. Correlation between Porosity and Fracture Mechanism in High Pressure Die Casting of AM60B Alloy. J Mater Sci Technol 2016;32:54-61.

https://doi.org/http://dx.doi.org/10.1016/j.jmst.2015.10.002. 
[40] Kareh KM, Lee PD, Atwood RC, Connolley T, Gourlay CM. Pore behaviour during semi-solid alloy compression: Insights into defect creation under pressure. Scr Mater 2014;89:73-6. https://doi.org/10.1016/j.scriptamat.2014.06.033.

[41] Dou K, Lordan E, Zhang YJ, Jacot A, Fan ZY. Numerical simulation of fluid flow, solidification and defects in high pressure die casting (HPDC) process. IOP Conf. Ser. Mater. Sci. Eng., vol. 529, 2019. https://doi.org/10.1088/1757-899X/529/1/012058.

[42] Cao H, Hao M, Shen C, Liang P. The influence of different vacuum degree on the porosity and mechanical properties of aluminum die casting. Vacuum 2017;146:278-81. https://doi.org/10.1016/j.vacuum.2017.09.048.

[43] Yuan Z, Guo Z, Xiong SM. Effect of as-cast microstructure heterogeneity on aging behavior of a high-pressure die-cast A380 alloy. Mater Charact 2018;135:278-86. https://doi.org/10.1016/j.matchar.2017.11.040.

[44] Niklas A, Orden S, Bakedano A, Silva M, Nogués E, Fernández-calvo AI. Effect of solution heat treatment on gas porosity and mechanical properties in a die cast step test part manufactured with a new AlSi10MnMg (Fe) secondary alloy. Mater Sci Eng A 2016;667:376-82. https://doi.org/10.1016/j.msea.2016.05.024.

[45] Zhang Y, Ma N, Le Y, Li S, Wang H. Mechanical properties and damping capacity after grain refinement in A356 alloy. Mater Lett 2005;59:2174-7. https://doi.org/10.1016/j.matlet.2005.02.058.

[46] Dong X, Zhang Y, Ji S. Enhancement of mechanical properties in high silicon gravity cast A1Si9Mg alloy refined by A13Ti3B master alloy. Mater Sci Eng A 2017;700:291-300. https://doi.org/10.1016/j.msea.2017.06.005.

[47] Zhang Y, Ji S, Fan Z. The Enhancement of Mechanical Properties of A356 Alloy Solidified at Lower Cooling Rate via Effectively Grain Refinement. Light Met 2017 2017:221-6. https://doi.org/10.1007/978-3-319-51541-0_30.

[48] Amirkhanlou S, Ji S, Zhang Y, Watson D, Fan Z. High modulus Al-Si-Mg-Cu/Mg2Si$\mathrm{TiB}_{2}$ hybrid nanocomposite: Microstructural characteristics and micromechanics-based analysis. J Alloys Compd 2017;694:313-24. https://doi.org/10.1016/j.jallcom.2016.10.016. [49] Ceschini L, Boromei I, Morri A, Seifeddine S, Svensson IL. Microstructure,tensile and fatigue properties of the $\mathrm{Al}-10 \% \mathrm{Si}-2 \% \mathrm{Cu}$ alloy with different $\mathrm{Fe}$ and $\mathrm{Mn}$ content cast under controlled conditions. J Mater Process Technol 2009;209:5669-79.

https://doi.org/10.1016/j.jmatprotec.2009.05.030.

[50] Seifeddine S, Johansson S, Svensson IL. The influence of cooling rate and manganese content on the $\beta$-A15FeSi phase formation and mechanical properties of Al-Si-based alloys. Mater Sci Eng A 2008;490:385-90. https://doi.org/10.1016/j.msea.2008.01.056.

[51] Goulart PR, Spinelli E, Os WR, Garcia A. Mechanical properties as a function of microstructure and solidification thermal variables of Al-Si castings. Mater Sci Eng A 2006;421:245-53. https://doi.org/10.1016/j.msea.2006.01.050.

[52] Caceres CH, Davidson CJ, Griffiths JR, Wang QG. The Effect of Mg on the Microstructure and Mechanical Behavior of Al-Si-Mg Casting Alloys. Metall Mater Trans A 1999;30:2611-8. https://doi.org/10.1007/s11661-999-0301-8

[53] Timelli G, Caliari D, Rakhmonov J. Influence of Process Parameters and Sr Addition on the Microstructure and Casting Defects of LPDC A356 Alloy for Engine Blocks. J Mater Sci Technol 2016;32:515-23. https://doi.org/10.1016/j.jmst.2016.03.010.

[54] Gutiérrez V, González G, García A. Thermal Analysis of Grain Refinement and Modification of an A356 cast alloy. Chem Mater Res 2014;6:52-63.

[55] Hegde S, Prabhu KN. Modification of eutectic silicon in Al-Si alloys. J Mater Sci 2008;43:3009-27. https://doi.org/10.1007/s10853-008-2505-5. 
[56] Deschamps A, Livet F, Bréchet Y. Influence of predeformation on ageing in an Al-ZnMg alloy-I. Microstructure evolution and mechanical properties. Acta Mater 1998;47:281-92. https://doi.org/10.1016/S1359-6454(98)00293-6.

[57] Ralston KD, Birbilis N, Weyland M, Hutchinson CR. The effect of precipitate size on the yield strength-pitting corrosion correlation in Al-Cu-Mg alloys. Acta Mater 2010;58:5941-8. https://doi.org/10.1016/j.actamat.2010.07.010.

[58] Sunde JK, Marioara CD, Helvoort ATJ Van, Holmestad R. The evolution of precipitate crystal structures in an Al-Mg-Si(-Cu) alloy studied by a combined HAADF-STEM and SPED approach. Mater Charact 2018;142:458-69. https://doi.org/10.1016/j.matchar.2018.05.031.

[59] Chen JH, Costan E, Huis MA van, Xu Q, Zandbergen HW. Atomic Pillar-Based Nanoprecipitates Strengthen AlMgSi alloy. Science 2006;312:416-20.

https://doi.org/10.1126/science.1124199.

[60] Lai YX, Jiang BC, Liu CH, Chen ZK, Wu CL, Chen JH. Low-alloy-correlated reversal of the precipitation sequence in Al-Mg-Si alloys. J Alloys Compd 2017;701:94-8.

https://doi.org/10.1016/j.jallcom.2017.01.095.

[61] Wang Y, Liu Z, Chen L, Wolverton C. First-principles calculations of $\mathrm{Mg}_{5} \mathrm{Si}_{6} / \alpha-\mathrm{Al}$ interfaces. Acta Mater 2007;55:5934-47. https://doi.org/10.1016/j.actamat.2007.06.045. [62] Zandbergen HW, Andersen SJ, Jansen J. Structure Determination of $\mathrm{Mg}_{5} \mathrm{Si}_{6}$ Particles in Al by Dynamic Electron Diffraction Studies. Science 1997;277:1221-5.

https://doi.org/10.1126/science.277.5330.1221. 